\title{
Seawater inhalation induces acute lung injury via ROS generation and the endoplasmic reticulum stress pathway
}

\author{
PENG-CHENG LI ${ }^{1 *}$, BO-RONG WANG ${ }^{1 *}$, CONG-CONG LI $^{1}$, XI LU $^{1}$, WEI-SHENG QIAN ${ }^{1}$, \\ YU-JUAN LI ${ }^{2}$, FA-GUANG JIN ${ }^{1}$ and DE-GUANG MU ${ }^{1}$ \\ ${ }^{1}$ Department of Respiratory Medicine, Tangdu Hospital, Fourth Military Medical University, Xi'an, Shaanxi 710038; \\ ${ }^{2}$ Department of Microbiology and Immunology, Shanxi Medical University, Taiyuan, Shanxi 030001, P.R. China
}

Received December 7, 2016; Accepted January 12, 2018

DOI: $10.3892 /$ ijmm.2018.3486

\begin{abstract}
Seawater (SW) inhalation can induce acute lung injury (ALI) and acute respiratory distress syndrome (ARDS). In the present study, SW induced apoptosis of rat alveolar epithelial cells and histopathological alterations to lung tissue. Furthermore, SW administration increased generation of reactive oxygen species (ROS), whereas pretreatment with the ROS scavenger, N-acetyl-L-cysteine (NAC), significantly decreased ROS generation, apoptosis and histopathological alterations. In addition, SW exposure upregulated the expression levels of glucose-regulated protein 78 (GRP78) and CCAAT/enhancer binding protein homologous protein $(\mathrm{CHOP})$, which are critical proteins in the endoplasmic reticulum (ER) stress response, thus indicating that SW may activate ER stress. Conversely, blocking ER stress with 4-phenylbutyric acid (4-PBA) significantly improved SW-induced apoptosis and histopathological alterations, whereas an ER stress inducer, thapsigargin, had the opposite effect. Furthermore, blocking ROS with NAC inhibited SW-induced ER stress, as evidenced by the downregulation of GRP78, phosphorylated (p)-protein kinase R-like ER kinase (PERK), p-inositol-requiring kinase $1 \alpha($ IRE1 $\alpha)$, p-50 activating transcription factor $6 \alpha$ and CHOP. In addition, blocking ER stress with 4-PBA decreased ROS generation. In conclusion, the present study indicated that ROS and ER stress pathways, which are involved in alveolar epithelial cell apoptosis, are important in the pathogenesis of SW-induced ALI.
\end{abstract}

Correspondence to: Professor De-Guang Mu or Professor Fa-Guang Jin, Department of Respiratory Medicine, Tangdu Hospital, Fourth Military Medical University, 1 Xinsi Road, Xi'an, Shaanxi 710038, P.R. China

E-mail: deguang@fmmu.edu.cn

E-mail: jinfag@fmmu.edu.cn

${ }^{*}$ Contributed equally

Key words: seawater, acute lung injury, endoplasmic reticulum stress, reactive oxygen species, apoptosis

\section{Introduction}

In recent years, drowning accidents have received growing attention. Approximately 50,000 people succumb to seawater (SW) drowning annually, and it has become the third leading cause of accidental death $(1,2)$. After SW drowning, victims are hypoxemic, due to severely damaged gas exchange; as a result, alveolar epithelial cells and pulmonary capillary epithelial cells are damaged, causing alveolar hemorrhage and exudate, pulmonary interstitial edema, and ventilation-perfusion mismatch, which ultimately lead to acute lung injury (ALI) and can further develop into acute respiratory distress syndrome (ARDS) (3).

Previous studies have suggested that apoptosis may be involved in the ALI/ARDS pathological process $(4,5)$. Our previous study confirmed that SW inhalation may lead to apoptosis of rat alveolar epithelial cells (6). However, there are few studies regarding the mechanism by which apoptosis contributes to SW-induced acute lung injury (SW-ALI) or acute respiratory distress syndrome (SW-ARDS).

Reactive oxygen species (ROS), including oxygen ions and peroxides, serve an important role in regulating cell growth, survival and death (7). Increased cellular ROS levels can activate various signaling pathways, resulting in DNA damage and apoptosis (8). Endoplasmic reticulum (ER) stress is the stress response of the body to external stimuli. When stimulated by external stimuli, cells activate ER stress and further activate signaling pathways, which induce cell death, inflammation and apoptosis (9). Numerous studies have suggested that increased ROS generation and ER stress interact with each other $(10,11)$.

The present study aimed to investigate whether ROS and ER stress pathways are involved in SW-induced apoptosis, which is in turn involved in the pathological process of SW-ALI and SW-ARDS.

\section{Materials and methods}

Reagents. Antibodies against phosphorylated (p)-protein kinase R-like ER kinase (PERK; ab192591), PERK (ab79483), inositol-requiring kinase $1 \alpha$ (IRE1 $\alpha$; ab37073), p-IRE1 $\alpha$ (ab48187), activating transcription factor $6 \alpha$ (ATF6 $\alpha$ ), p-50ATF6 $\alpha$ (ab37149), glucose-regulated protein 78 (GRP78; ab21685), CCAAT/enhancer binding protein homologous 
protein (CHOP; ab11419), p-c-Jun N-terminal kinase (JNK; ab124956), JNK (ab179461) and caspase-3 (ab13847) were purchased from Abcam (Cambridge, UK). N-acetyl L-cysteine (NAC), 4-phenylbutyric acid (4-PBA) and thapsigargin (Thap) were also purchased from Abcam. The Annexin V-fluorescein isothiocyanate (FITC) apoptosis detection kit was purchased from Roche Diagnostics (Indianapolis, IN, USA). Cell Counting kit-8 (CCK-8) and 2',7'-dichlorofluorescein diacetate (DCFH-DA) were purchased from Beyotime Institute of Biotechnology (Shanghai, China). SW (osmolality, $1,300 \mathrm{mmol} / \mathrm{l} ; \mathrm{pH} 8.2$; relative density 1.05 ; salt content, $34.421 \% ; \mathrm{NaCl}, 26.518 \mathrm{~g} / \mathrm{l} ; \mathrm{MgSO}_{4}, 3.305 \mathrm{~g} / \mathrm{l} ; \mathrm{MgCl}_{2}, 2.447 \mathrm{~g} / \mathrm{l}$; $\mathrm{CaCl}_{2}, 1.141 \mathrm{~g} / 1 ; \mathrm{KCl}, 0.725 \mathrm{~g} / 1 ; \mathrm{NaHCO}_{3}, 0.202 \mathrm{~g} / 1$; and $\mathrm{NaBr}$, $0.083 \mathrm{~g} / \mathrm{l}$ ) was prepared based on the overall composition of the East China Sea, which was provided by the Chinese Ocean Bureau (Beijing, China).

Animal preparation. Male Sprague-Dawley rats (age, 5-7 weeks; weight, $200 \pm 20 \mathrm{~g}$ ) were obtained from the Animal Center of the Fourth Military Medical University (Xi'an, China). The rats were maintained in a temperature-controlled room $\left(20-22^{\circ} \mathrm{C}\right)$ with $40-50 \%$ humidity, under a 12 -h light/dark cycle. All rats were given ad libitum access to standard laboratory chow and water. Prior to experimentation, rats were fasted for $12 \mathrm{~h}$, but were allowed free access to water. The present study was approved by the Animal Care and Use Committee of the Fourth Military Medical University, and experiments were conducted in accordance with the National Institutes of Health guidelines regulating the Care and Use of Laboratory Animals (12).

Firstly, 25 Sprague-Dawley rats were randomly divided into the following five groups: Normal control group (were treated as SW groups, but no liquid was injected into the trachea), 2-h SW group (2 h), 4-h SW group (4h), 6-h SW group $(6 \mathrm{~h})$ and 8 -h SW group $(8 \mathrm{~h})$. The rats were anesthetized with $20 \%$ urethane $(1.0 \mathrm{~g} / \mathrm{kg})$, administered intraperitoneally, prior to treatment with SW. SW (4 ml/kg body weight) was injected into both lungs though the trachea at a constant speed over $4 \mathrm{~min}$. The rats were kept in a supine and 30-degree head-up position during the experiment. Secondly, 30 Sprague-Dawley rats (independent of the initial 25 rats) were randomly divided into the following six groups: Control group, SW group, NAC control group $(150 \mathrm{mg} / \mathrm{kg})$, NAC + SW group, 4-PBA control group $(30 \mathrm{mg} / \mathrm{kg})$ and $4-\mathrm{PBA}+\mathrm{SW}$ group. The rats were pretreated with NAC or 4-PBA, which were administered intraperitoneally, $2 \mathrm{~h}$ prior to SW administration. Rats were sacrificed $4 \mathrm{~h}$ after SW administration. Rats in the control, NAC and 4-PBA groups were treated with saline instead of SW. Finally, the rats were sacrificed by an overdose of anesthesia at the indicated time-points; subsequently, lung tissues were harvested and processed.

A549 cell culture and treatment. Human lung alveolar epithelial A549 cells were purchased from American Type Culture Collection (Manassas, VA, USA) and were cultured in RPMI-1640 medium (Hyclone, Logan, UT, USA) supplemented with $100 \mu \mathrm{g} / \mathrm{ml}$ streptomycin, $100 \mathrm{U} / \mathrm{ml}$ penicillin and $10 \%$ fetal bovine serum (Sijiqing, Hangzhou, China) in a humidified atmosphere containing $95 \%$ air and $5 \% \mathrm{CO}_{2}$ at $37^{\circ} \mathrm{C}$. For the subsequent experiments, cells were collected during the logarithmic growth phase under the same conditions. A549 cells $\left(1 \times 10^{4} / \mathrm{ml}\right)$ were inoculated into 6-well plates in culture medium overnight, after which, $\mathrm{SW}$ was added at final concentrations of 10,20,40 and $60 \%$ for $4 \mathrm{~h}$, or $25 \%$ for $2,4,6$ or 8 h. NAC ( $5 \mathrm{mM}), 4$-PBA ( $2 \mathrm{mM})$ and Thap (150 nM) were prepared in advance and added to cells $2 \mathrm{~h}$ prior to $\mathrm{SW}$ administration. Mean fluorescence intensity was analyzed using ImageJ software (version 1.51j8; National Institutes of Health, Bethesda, MD, USA).

ROS assay. The DCFH-DA probe was used to detect ROS generation. Briefly, A549 cells were inoculated into plates and were treated when they reached $75 \%$ confluence. Subsequently, cells were incubated with DCFH-DA $(10 \mu \mathrm{M})$ at $37^{\circ} \mathrm{C}$ for 45 min. Finally, cells were washed three times with PBS and imaged under a fluorescence microscope.

Lung wet-to-dry weight (W/D) ratio. The lung W/D ratio is considered an index of pulmonary edema. The left lungs ( $n=5)$ were weighed immediately after the rats were sacrificed, and were then subjected to desiccation at $55^{\circ} \mathrm{C}$ for $72 \mathrm{~h}$ to determine the dry weight. The lung W/D ratio was calculated by dividing the wet weight by the dry weight.

Histopathological examination. To visually evaluate the severity of lung injury, the right lower lungs of the rats were separated and fixed with $10 \%$ formalin at the indicated time-points. Subsequently, the tissues were embedded in paraffin and cut into $5 \mu \mathrm{m}$ sections, which were mounted on silanized slides and stained with hematoxylin and eosin (H\&E). The sections were observed using an Olympus microscope (Olympus, Tokyo, Japan).

Immunohistochemical analysis of GRP78 expression in rat lungs. Rat lung sections were deparaffinized and rehydrated, after which they were incubated in $3 \%$ hydrogen peroxide for $10 \mathrm{~min}$ to quench endogenous peroxidase activity. After boiling the sections in $0.01 \mathrm{~mol} / 1$ citrate buffer (microwave oven heating, at high fire for $2 \mathrm{~min}$ and medium fire for $8 \mathrm{~min}$ ) for antigen recovery, slides were incubated with anti-GRP78 antibody (1:200) at $4^{\circ} \mathrm{C}$ for 1 night. Subsequently, the sections were incubated with horseradish peroxidase-conjugated secondary antibody at room temperature for $1 \mathrm{~h}$, as described in the instructions provided in the immunohistochemistry kit (1:400; \#13079; Cell Signaling Technology, Inc., Danvers, MA, USA). The sections were observed using an Olympus microscope (Olympus, Tokyo, Japan).

Flow cytometry. A549 cells undergoing apoptosis were digested with parenzyme at the indicated time-points, and were then washed twice with PBS prior to being resuspended in Annexin binding buffer. A549 cell apoptosis was investigated following the addition of propidium iodide and FITC-conjugated Annexin V, according to the manufacturer's protocol. The results were analyzed by flow cytometry (EXP032; Beckman Coulter, Brea, CA, USA).

Western blot analysis. Right upper lung tissues and A549 cells were lysed with protein extraction reagent (P0013; Beyotime Institute of Biotechnology) according to the manufacturer's 
protocol. Protein concentration was determined using BCA protein quantification kits (ab102536; Abcam).Proteins (30 $\mu \mathrm{g}$ proteins in each group) were separated by $12 \%$ gradient SDS-PAGE and were transferred to polyvinylidene fluoride membranes. Nonspecific binding was blocked with $10 \%$ non-fat dry milk in Tris-buffered saline (TBS) at room temperature for $1 \mathrm{~h}$. The membranes were then incubated overnight at $4^{\circ} \mathrm{C}$ with anti-PERK (1:1,000 dilution), anti-p-PERK (1:1,000 dilution), anti-GRP78 (1:1,000 dilution), anti-JNK (1:1,000 dilution), anti-p-JNK (1:1,000 dilution), anti-CHOP (1:1,000 dilution), anti-IRE1 $\alpha$ (1:1,000 dilution), anti-p-IRE1 $\alpha$ (1:1,000 dilution), anti-p-50ATF6 $\alpha$ (1:1,000 dilution), anti-cleaved caspase-3 (1:1,000 dilution) and anti-GAPDH (1:1,000 dilution; ab8245; Abcam). After washing with TBS containing 20\% Tween-20 (20\% Tween-20: TBS $=2.6: 1,000)$, the membranes were incubated with an HRP-labeled goat anti-rabbit IgG secondary antibody (1:7,500 dilution; A0208; Beyotime Institute of Biotechnology) at room temperature for $1.5 \mathrm{~h}$. The blots were visualized using an enhanced chemiluminescent detection system (Bio-Rad, Hercules, CA, USA).

TUNEL detection of lung cell apoptosis. TUNEL assay was used to detect apoptotic cells in rat lung tissues via an In Situ Cell Death Detection kit (MK500; Takara, Otsu, Japan) according to the manufacturer's protocol. Briefly, sections were incubated with proteinase $\mathrm{K}$ for $30 \mathrm{~min}$ after dewaxing and rehydration. TUNEL staining results were analyzed by imageJ software. The sections were then incubated with TUNEL solution for $60 \mathrm{~min}$ and were incubated with alkaline phosphatase conversion solution for $30 \mathrm{~min}$. Apoptotic cells were detected by incubation with 3,3'-diaminobenzidine tetrahydrochloride chromogen for $20 \mathrm{~min}$, and the results were analyzed using a digital imaging system.

Statistical analysis. All data are presented as the means \pm standard error of the mean, and each experiment was performed at least three times. Multiple groups were compared using one-way analysis of variance followed by a Tukey's test. Statistical analyses were conducted using GraphPad Prism software version 5.01 (GraphPad Software, Inc., La Jolla, CA, USA). $\mathrm{P}<0.05$ was considered to indicate a statistically significant difference.

\section{Results}

SW exposure induces pulmonary edema, histological alterations and apoptosis in rat lungs. To evaluate the degree of pulmonary edema induced by SW aspiration, lung W/D ratios were calculated following various durations of SW exposure. The W/D ratio was higher in the SW group compared with in the normal group. This difference was significant at $2 \mathrm{~h}$ and then gradually decreased (Fig. 1A). To investigate alterations in the structure of pulmonary tissue following SW aspiration, histological analysis was performed. The results indicated that disruption of the lung alveolar architecture occurred in response to SW aspiration; this disruption peaked at $4 \mathrm{~h}$ and then gradually decreased (Fig. 1B).

In order to assess whether SW aspiration induced apoptosis in rat lungs, lung tissue sections were stained according to the TUNEL assay. The degree of apoptosis clearly paralleled the histological alterations (Fig. 1C and D). These results suggested that SW aspiration may induce edema and ALI in rat lungs, which may be associated with apoptosis.

SW inhibits cell growth and induces apoptosis of A549 cells. To investigate the cytotoxic effects of SW on A549 cells, the CCK-8 assay was used to evaluate the extent of cell growth inhibition induced by SW. Notably, following treatment with $20,40,60$ or $80 \%$ SW for $4 \mathrm{~h}$, cell viability decreased in a dose-dependent manner (Fig. 2A). Subsequently, A549 cells were treated with $25 \% \mathrm{SW}$ for $2,4,6$ or $8 \mathrm{~h}$, and a time-dependent decrease in cell viability was detected (Fig. 2B). These findings suggested that SW may induce cell growth inhibition, and that the cytotoxic effects of SW on A549 cells may be associated with SW dose and treatment time.

The present study also assessed whether SW had a proapoptotic effect in vitro (Fig. 2C-F). Following treatment with 20, 40, 60 or $80 \%$ SW for 4 h, apoptosis of A549 cells was measured by flow cytometry. The results indicated that the percentage of apoptotic cells was increased as the concentration of SW increased (Fig. 2C and E). Furthermore, a time-dependent increase in cell apoptosis was detected when cells were treated with $25 \% \mathrm{SW}$ for various durations (Fig. 2D and F). The results of the cell apoptosis and growth inhibition experiments were similar, thus suggesting that SW induces cell growth inhibition, which may be associated with apoptosis.

SW induces ROS generation in A549 cells. Previous studies have indicated that numerous undesirable external stimuli can trigger ROS generation, and that ROS serve an important role in cell injury and the development of several diseases $(13,14)$. Therefore, it was predicted that SW may induce the generation of ROS in A549 cells. To verify this hypothesis, the present study assessed the levels of ROS using the DCFH-DA probe following treatment of A549 cells with various concentrations of SW (20,40 or 60\%) for $4 \mathrm{~h}$, or with $25 \% \mathrm{SW}$ for various durations $(2,4,6$ or $8 \mathrm{~h}$ ). Subsequently, images were captured using fluorescence microscopy and were evaluated (Fig. 3). SW significantly increased ROS levels in a dose-dependent (Fig. 3A and D) and time-dependent manner (Fig. 3B and E). Notably, SW-induced ROS generation was markedly impaired when cells were pretreated with the ROS inhibitor NAC (5 mM) for $2 \mathrm{~h}$ (Fig. 3C and F). These results suggested that SW stimulation can trigger ROS generation, which may affect cell survival.

ROS are implicated in SW-induced cell apoptosis and growth inhibition in vivo and in vitro. Previous studies have reported that ROS generation is closely associated with apoptosis $(15,16)$. Therefore, the present study investigated whether ROS are involved in SW-induced cell growth inhibition and apoptosis (Fig. 4). Rats were administered a ROS scavenger, NAC (150 mg/kg), via intraperitoneal injection $2 \mathrm{~h}$ prior to SW inhalation; subsequently, the levels of cell apoptosis were evaluated using a TUNEL assay. The results revealed that pretreatment with NAC attenuated SW-induced apoptosis (Fig. 4A and C). Similarly, using flow cytometry, the results indicated that pretreatment with NAC $(5 \mathrm{mM})$ for $2 \mathrm{~h}$ significantly alleviated $\mathrm{SW}$-induced apoptosis of A549 cells (Fig. 4B and D). Subsequently, the present study detected 

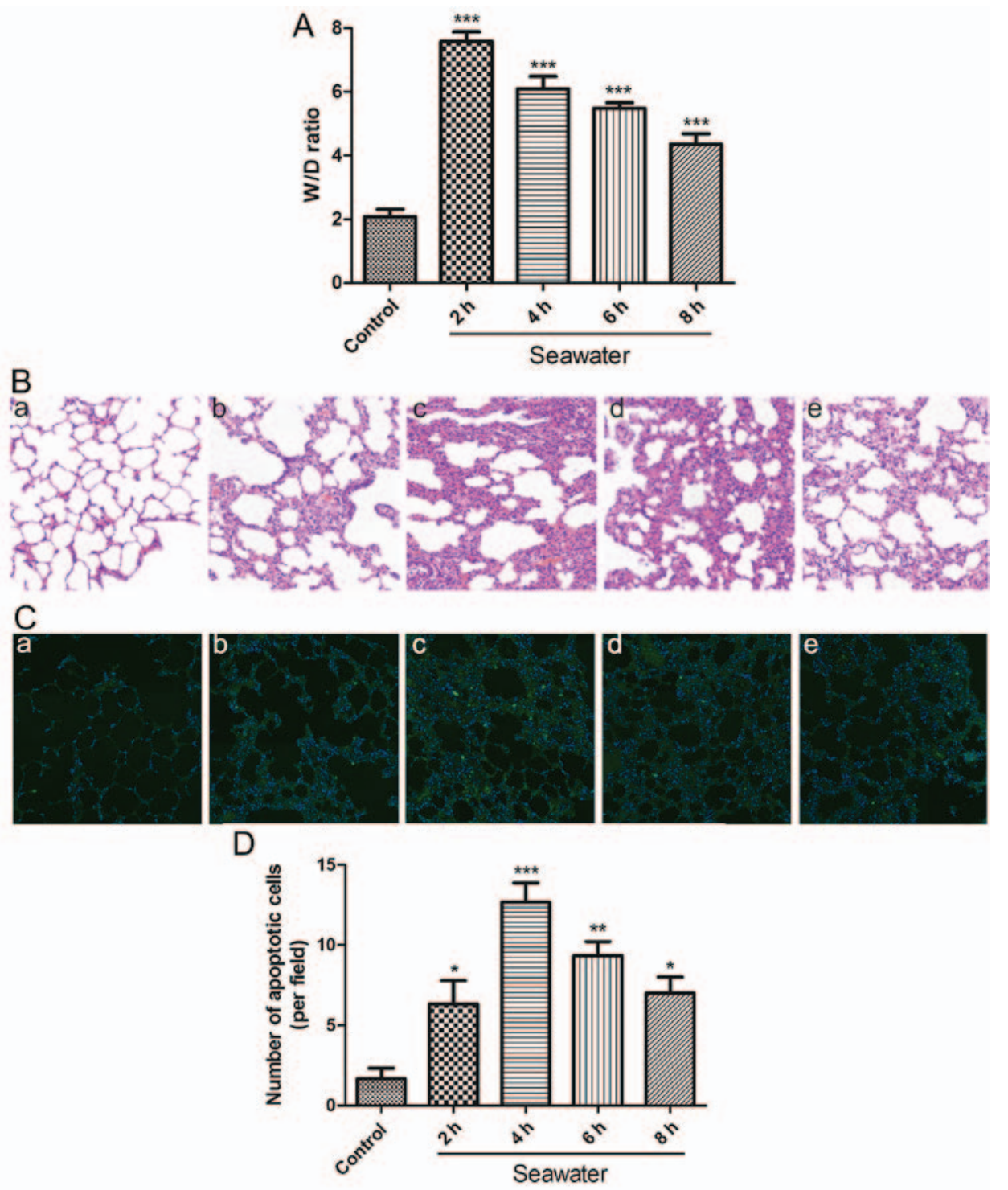

Figure 1. SW induces pulmonary edema, histopathological alterations and apoptosis in rat lungs. (A) Time-dependent effects of SW on lung W/D ratio (n=5). (B) Time-dependent effects of SW on lung histopathological alterations in rats (hematoxylin and eosin staining; original magnification, x20). (a) Control, and (b) $2 \mathrm{~h}$, (c) $4 \mathrm{~h}$, (d) $6 \mathrm{~h}$ and (e) $8 \mathrm{~h} \mathrm{SW}$ groups. (C) SW aspiration-induced apoptosis in rat lungs [TUNEL assay staining; original magnification, x20). (a) Control, and (b) $2 \mathrm{~h}$, (c) $4 \mathrm{~h}$, (d) $6 \mathrm{~h}$ and (e) $8 \mathrm{~h} \mathrm{SW}$ groups. (D) Number of apoptotic cells per field in (C). Data are presented as the means \pm standard error of the mean, $\mathrm{n}=5 .{ }^{*} \mathrm{P}<0.05,{ }^{* *} \mathrm{P}<0.01$ and ${ }^{* * *} \mathrm{P}<0.001$ vs. the control group. W/D, wet/dry; SW, seawater.

the expression of apoptosis-associated proteins (caspase-3 and $\mathrm{p}-\mathrm{JNK}$ ) in A549 cells. SW administration significantly increased the protein expression levels of caspase-3 and p-JNK; however, NAC pretreatment reversed these effects (Fig. 4E-G). Furthermore, similar results were detected with regards to SW-induced inhibition of A549 cell growth (Fig. 4H). These results indicated that ROS generation may be involved in $\mathrm{SW}$-induced cell apoptosis and growth inhibition.

$S W$ administration activates ER stress in vitro and in vivo. To determine whether SW administration can activate ER stress, the present study detected the expression levels of GRP78 and $\mathrm{CHOP}$, which are considered essential proteins in the ER stress response (17-19). The results suggested that as the length of SW exposure increased, GRP78 and CHOP expression increased and peaked at $4 \mathrm{~h}$ before gradually decreasing in vivo (Fig. $5 \mathrm{~A}$ ). In vitro, $\mathrm{SW}$ exposure time-dependently increased the expression of GRP78 and CHOP (Fig. 5B). In addition, A549 cells were pretreated with an ER stress inhibitor, 4-PBA (2 mM), $2 \mathrm{~h}$ prior to $\mathrm{SW}$ exposure. Treatment with an ER stress inducer, Thap (150 $\mathrm{nM})$, for $4 \mathrm{~h}$ was used as a positive control, after which the expression levels of GRP78 and CHOP were detected. The results revealed that 4-PBA $(30 \mathrm{mg} / \mathrm{kg})$ pretreatment clearly reduced SW-induced expression of GRP78 and CHOP; however, Thap treatment increased GRP78 and CHOP expression (Fig. 5C). In addition, rats were pretreated with 4-PBA $2 \mathrm{~h}$ prior to SW inhalation and immunohistochemistry performed to detect GRP78 in rat lungs. 4-PBA pretreatment reduced SW-induced expression of GRP78 in rat lungs (Fig. 5D). These results suggested that $\mathrm{SW}$ administration may activate ER stress.

ER stress is implicated in SW-induced cell apoptosis and growth inhibition in vivo and in vitro. Numerous studies have suggested that ER stress is involved in several cellular activities, particularly apoptosis (20-22). Therefore, the present study investigated whether ER stress is involved in SW-induced cell injury (Fig. 6). 

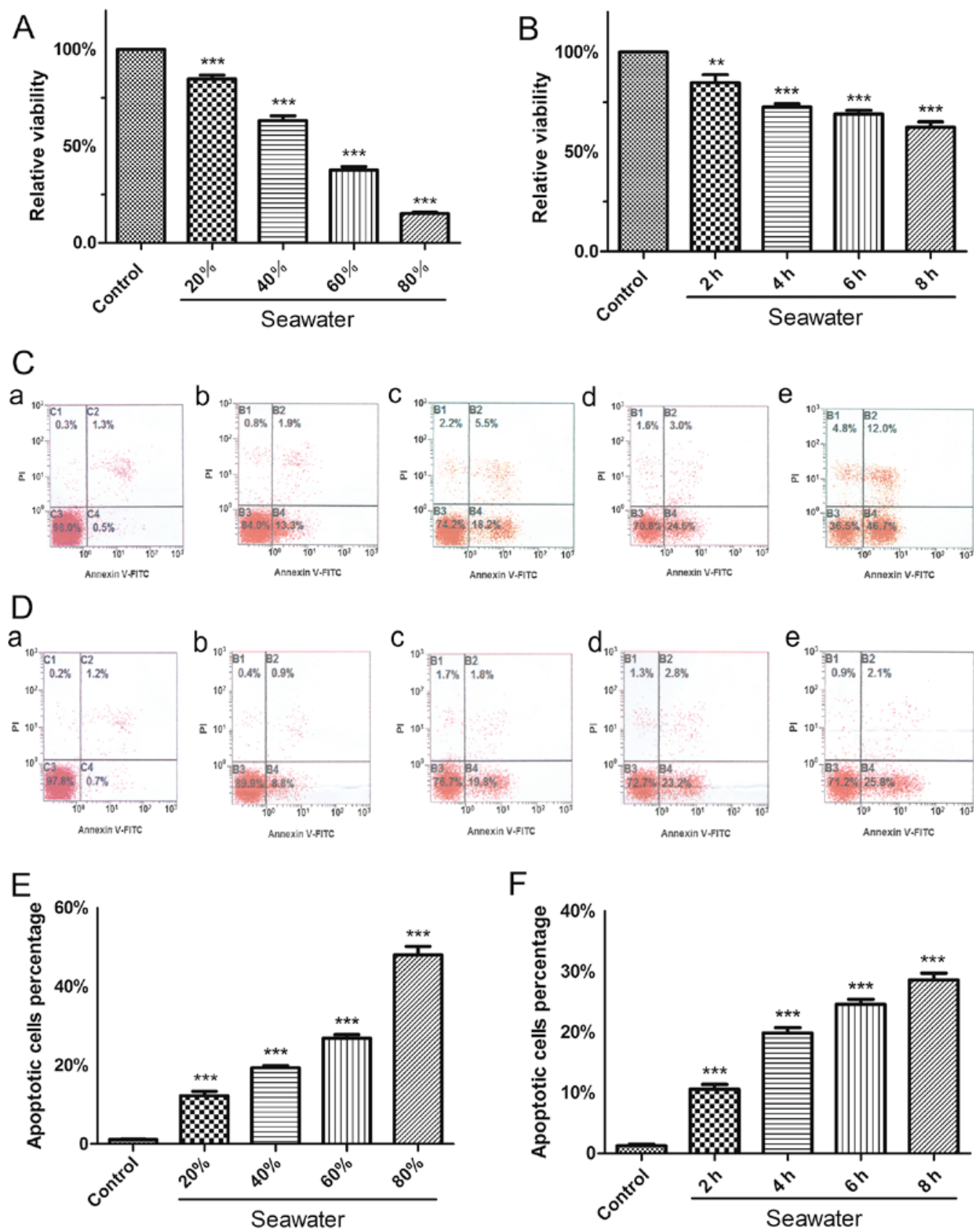

Figure 2. SW inhibits growth and induces apoptosis of A549 cells. (A) Dose-dependent effects of SW on cell viability. A549 cells were treated with various concentrations of SW (20,40,60 and 80\%) for $4 \mathrm{~h}$, and Cell Counting kit-8 assay was used to measure cell viability. (B) Time-dependent effects of SW on cell viability. The cells were treated with $25 \% \mathrm{SW}$ for various durations $(2,4,6$ and $8 \mathrm{~h}$ ), and cell viability was measured as in (A). (C) Dose-dependent effects of SW on cell apoptosis. A549 cells were treated as in (A); subsequently, cell apoptosis was assessed by Annexin V-FITC/PI staining. (a) Control, and (b) 20\%, (c) $40 \%$, (d) $60 \%$ and (e) $80 \%$ SW groups. (D) Time-dependent effects of SW on cell apoptosis. A549 cells were treated as in (B), and cell apoptosis was measured as in (C). (a) Control, and (b) $2 \mathrm{~h}$, (c) $4 \mathrm{~h}$, (d) $6 \mathrm{~h}$ and (e) $8 \mathrm{~h} \mathrm{SW}$ groups. (E) Percentage of apoptotic cells in (C). (F) Percentage of apoptotic cells in (D). Data are presented as the means \pm standard error of the mean, $n=5$. ${ }^{* * * *} \mathrm{P}<0.001$ vs. the control group. FITC, fluorescein isothiocayanate; PI, propidium iodide; SW, seawater.

The rats were intraperitoneally injected with 4-PBA $2 \mathrm{~h}$ prior to SW inhalation, after which cell apoptosis was evaluated using a TUNEL assay. The results indicated that pretreatment with 4-PBA attenuated SW-induced apoptosis (Fig. 6A and C). Similarly, using flow cytometry, pretreatment with 4-PBA $(2 \mathrm{mM})$ for $2 \mathrm{~h}$ significantly alleviated $\mathrm{SW}$-induced apoptosis of A549 cells; conversely, Thap, an ER inducer, increased apoptosis (Fig. 6B and D). Subsequently, the present study detected the expression of apoptosis-associated proteins, caspase- 3 and p-JNK. Notably, 4-PBA significantly reduced the expression of apoptosis-associated proteins, whereas Thap increased their expression (Fig. 6E-G). Furthermore, similar effects were detected on SW-induced growth inhibition (Fig. 6H). Collectively, these results revealed that $\mathrm{SW}$-induced cell growth inhibition and apoptosis in rat lung tissues and A549 cells are at least somewhat dependent on ER stress signaling pathways.

SW administration activates ROS and ER stress, which interact to induce cell damage. To investigate the association between ER stress and SW-induced ROS generation, A549 cells were 
A
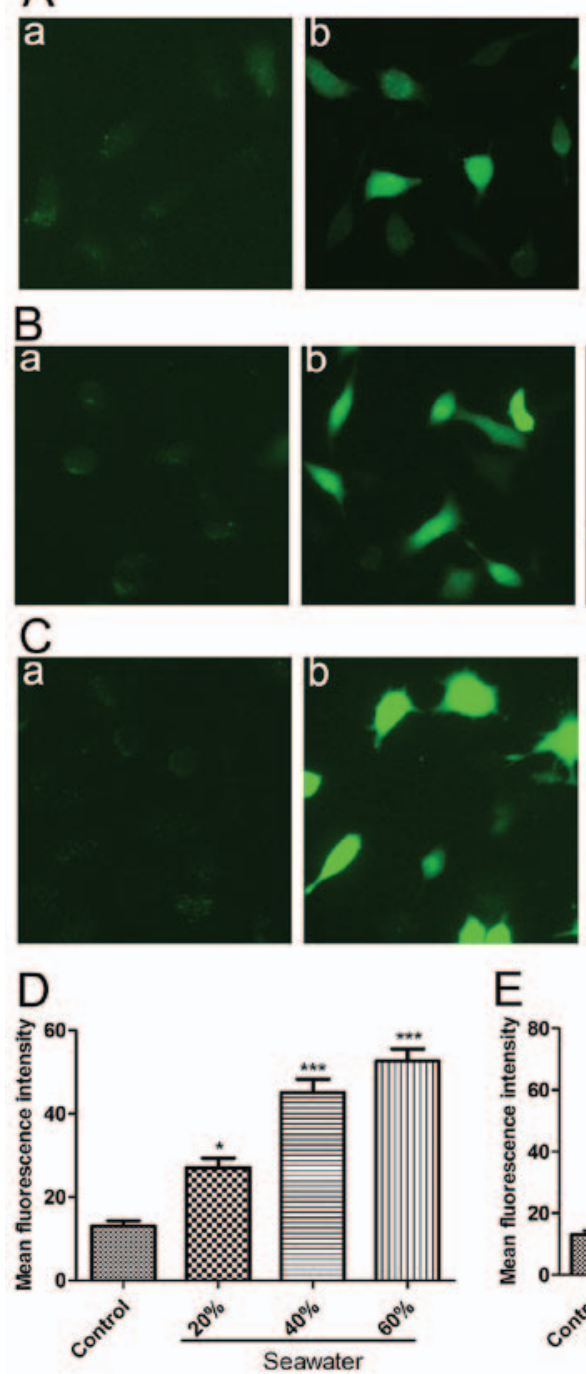
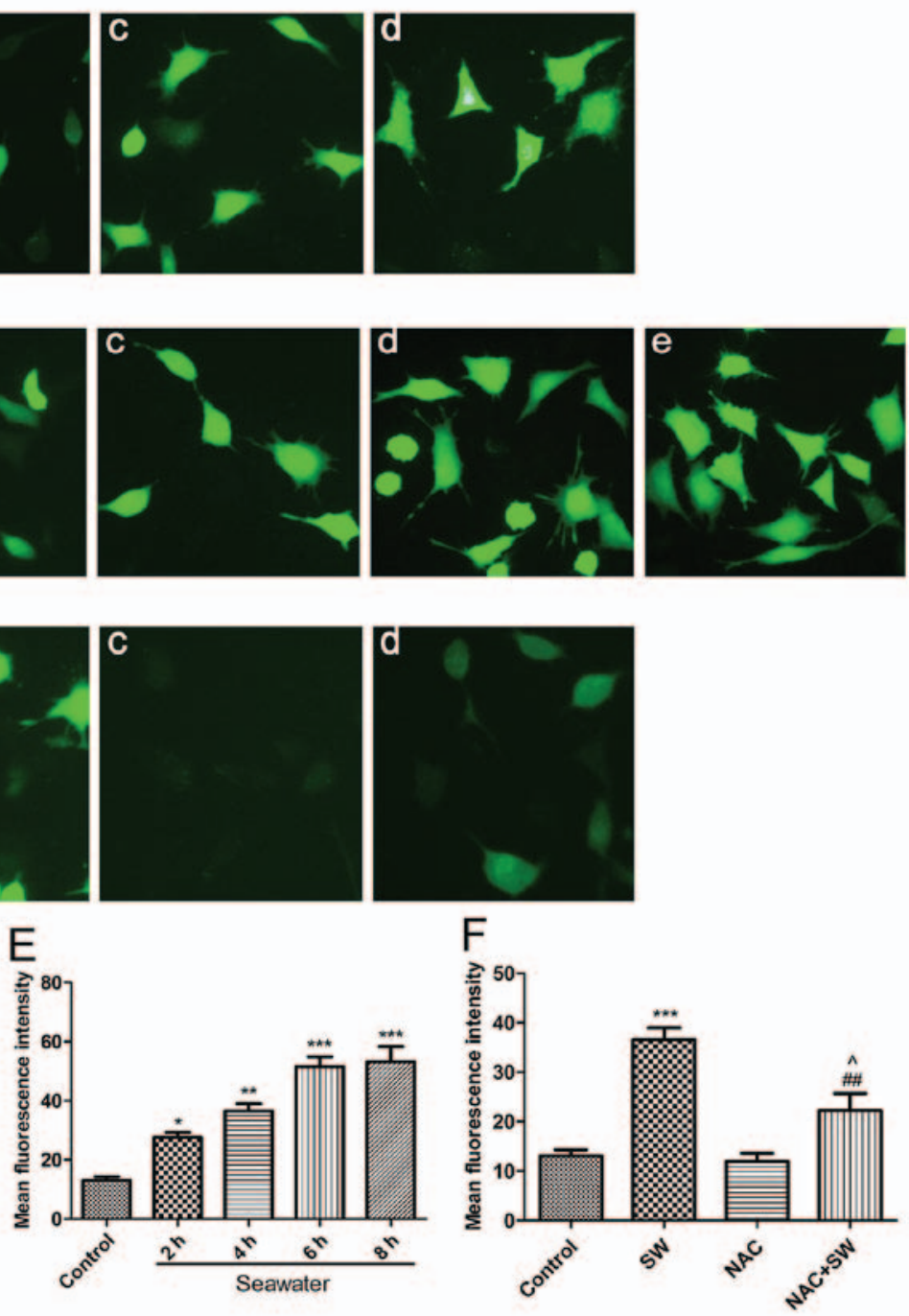

Figure 3. SW triggers ROS generation. (A) Dose-dependent effects of SW on cellular ROS levels. A549 cells were treated with the indicated concentrations of SW for $4 \mathrm{~h}$, and cellular ROS levels were assessed using 2',7'-dichlorofluorescein diacetate and were visualized with a fluorescence microscope. (a) Control, and (b) $20 \%$, (c) $40 \%$, (d) $60 \%$ and (e) $80 \%$ SW groups (magnification, x100). (B) Time-dependent effects of SW on cellular ROS levels. A549 cells were treated with $25 \%$ SW for various durations, and cellular ROS levels were assessed as described in (A). (a) Control, and (b) 2 h, (c) 4 h, (d) 6 h and (e) 8 h SW groups (magnification, x100). (C) Effects of NAC on SW-induced ROS generation. Following pretreatment with 5 mM NAC for 2 h, cells were treated with $25 \%$ SW for $4 \mathrm{~h}$ and cellular ROS levels were assessed. (a) Control, (b) SW, (c) NAC and (d) NAC + SW groups (magnification, x100). (D) Mean fluorescence intensity of (A) was analyzed using ImageJ software. (E) Mean fluorescence intensity of (B) was analyzed using ImageJ software. (F) Mean fluorescence intensity of (C) was analyzed using ImageJ software. Data are presented as the means \pm standard error of the mean, $\mathrm{n}=5$. ${ }^{*} \mathrm{P}<0.05$, ${ }^{* *} \mathrm{P}<0.01$ and ${ }^{* * * *} \mathrm{P}<0.001 \mathrm{vs}$. the control group; ${ }^{\# \#} \mathrm{P}<0.01$ vs. the $\mathrm{SW}$ group; and ${ }^{\wedge} \mathrm{P}<0.05$ vs. the NAC group. NAC, N-acetyl-L-cysteine; ROS, reactive oxygen species; SW, seawater.

pretreated with a ROS scavenger, NAC (5 mM), $2 \mathrm{~h}$ prior to SW exposure and the expression levels of ER stress-associated proteins, GRP78 (Fig. 7A), p-50ATF-6 $\alpha$ (Fig. 7B), p-IRE1 $\alpha$ (Fig. 7C), p-PERK (Fig. 7D) and CHOP (Fig. 7E), were detected. The SW-induced expression of these proteins was attenuated following NAC pretreatment, thus suggesting that SW-induced ROS generation may activate ER stress.

The present study also pretreated A549 cells with an ER stress inhibitor, 4-PBA (2 mM), prior to SW exposure, and with an ER stress inducer Thap (150 nM) as a positive control; subsequently, the levels of cellular ROS were detected. Notably, ROS generation was attenuated by 4-PBA pretreatment, whereas it was enhanced by Thap treatment (Fig. 7F and G) revealing that ER stress is involved in ROS generation in response to SW administration. These results indicated that SW-induced ER stress and ROS generation may interact with each other to induce cell injury.

\section{Discussion}

Drowning has gradually become one of the most common causes of accidental death worldwide (1). Drowning victims experience hypoxia, because $S W$ inhalation obstructs the airway. In addition, SW with high osmolality can directly damage alveolar epithelial cells. These factors induce ALI or ARDS. The present study demonstrated that SW inhalation could induce apoptosis in vivo and in vitro. The results indicated that SW exposure induced cell apoptosis and growth inhibition, which are key factors in SW-ALI and SW-ARDS, via ROS generation and ER stress pathways. These findings were supported by the following: i) SW dose- and time-dependently inhibited A549 cell growth and induced cell apoptosis; furthermore, SW inhalation increased the W/D ratio of rat lungs and induced histopathological alterations; ii) $\mathrm{SW}$ exposure stimulated ROS production, and inhibiting ROS 
A
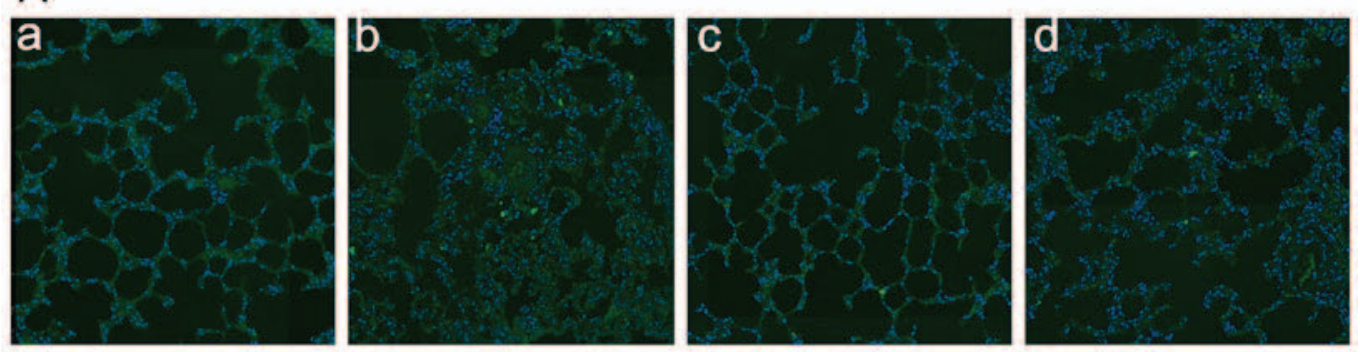

B
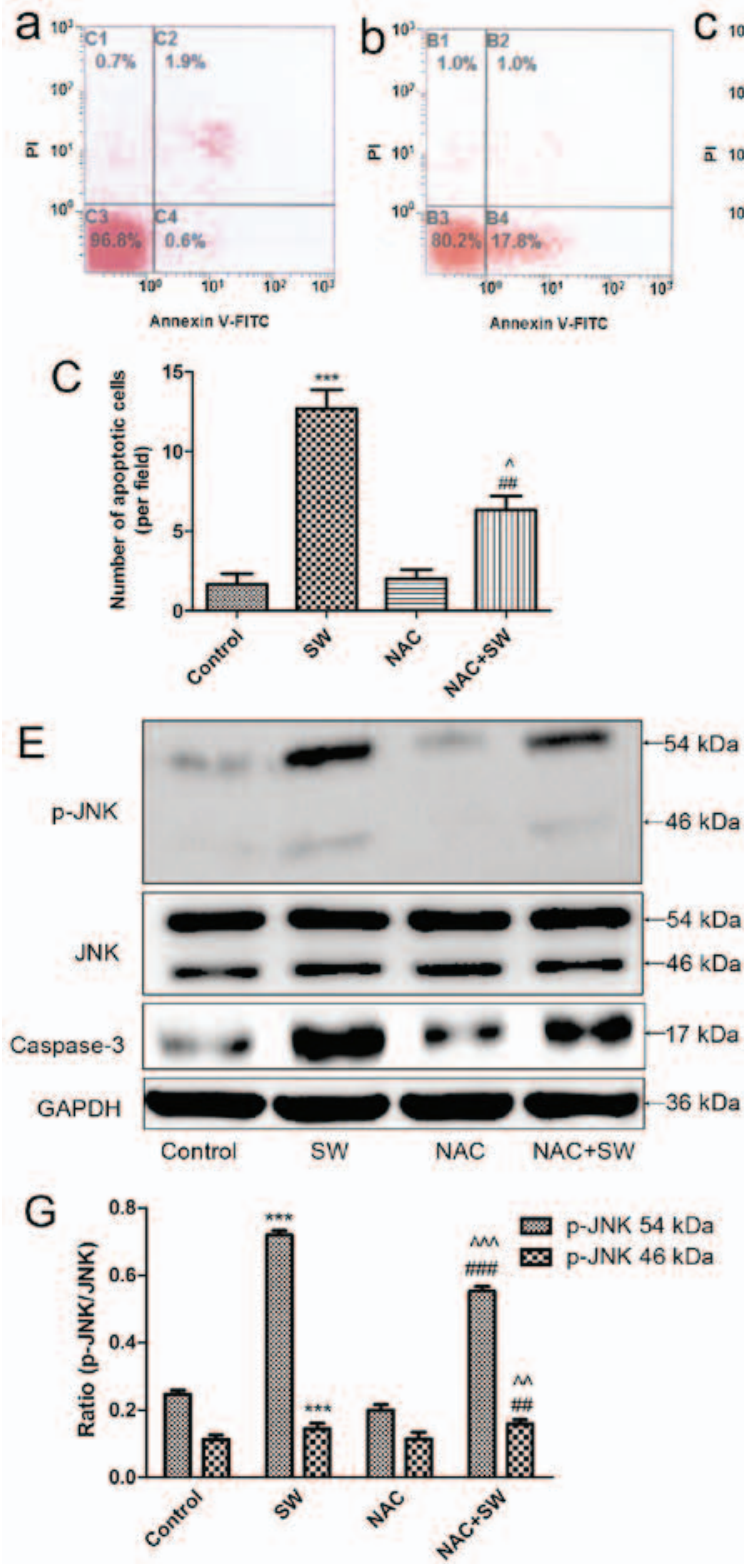
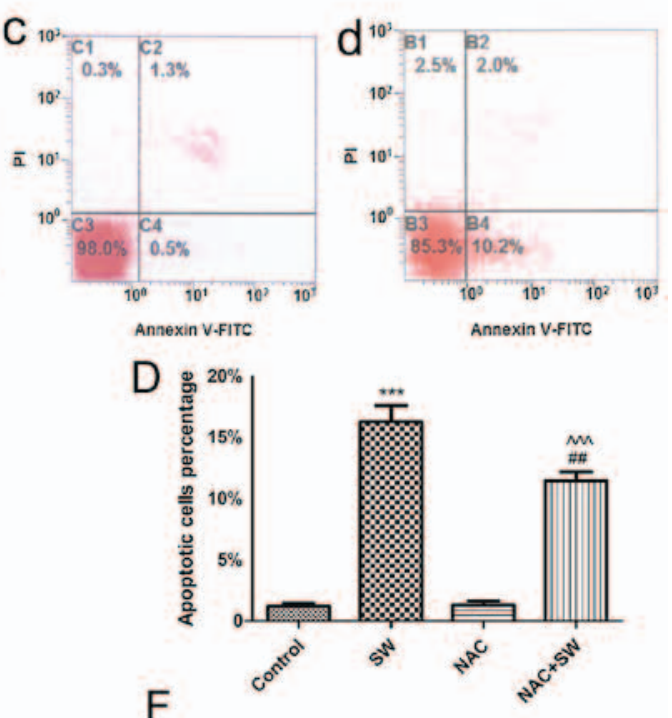

$\mathrm{F}$
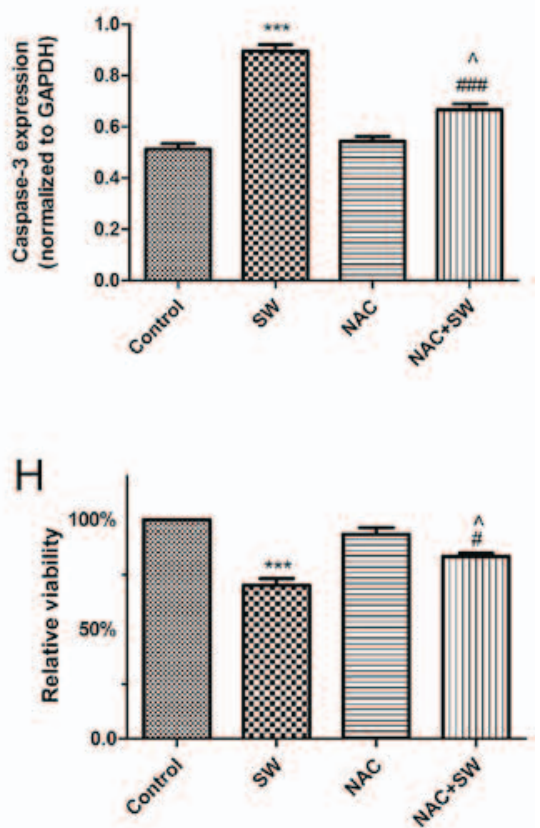

Figure 4. SW-induced growth inhibition and apoptosis depend on ROS. (A) Effects of NAC (150 mg/kg) pretreatment on SW-induced apoptosis in rats (TUNEL staining; magnification, x10). (B) Effects of NAC (5 mM) on SW-induced apoptosis of A549 cells (Annexin V-FITC/PI staining). (a) Control, (b) SW, (c) NAC and (d) NAC + SW groups. (C) Number of apoptotic cells per field in (A). (D) Percentage of apoptotic cells in (B). (E-G) Effects of NAC $(5 \mathrm{mM})$ on the expression of the apoptosis-associated proteins caspase-3 and p-JNK in A549 cells. (H) Effects of NAC on SW-induced cell growth inhibition (Cell Counting kit- 8 assay). Data are presented as the means \pm standard error of the mean, $\mathrm{n}=5$. ${ }^{* * *} \mathrm{P}<0.001$ vs. the control group; ${ }^{\#} \mathrm{P}<0.05$ and ${ }^{\# \#} \mathrm{P}<0.01 \mathrm{vs}$. the SW group; ${ }^{\wedge} \mathrm{P}<0.05,{ }^{\wedge} \mathrm{P}<0.01$ and ${ }^{\wedge \wedge} \mathrm{P}<0.001$ vs. the NAC group. FITC, fluorescein isothiocyanate; JNK, c-Jun N-terminal kinae; NAC, N-acetyl-L-cysteine; p-JNK, phosphorylated-JNK; PI, propidium iodide; ROS, reactive oxygen species; SW, seawater.

generation with NAC significantly improved SW-induced apoptosis and growth inhibition; and iii) SW administration induced
ER stress, whereas suppressing ER stress with 4-PBA alleviated SW-induced apoptosis and cell growth inhibition. 
A
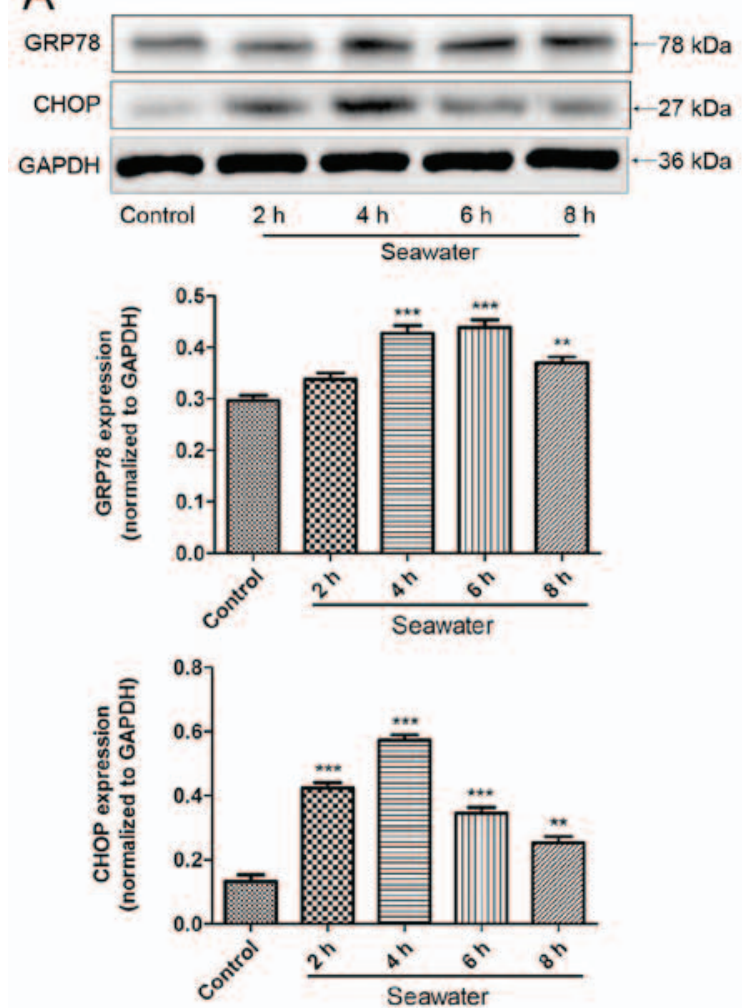

C

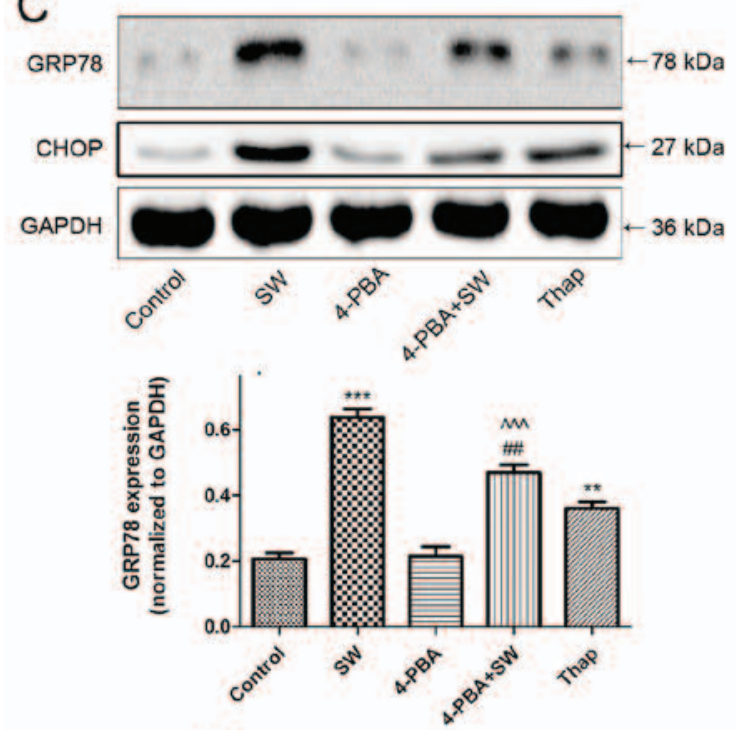

B
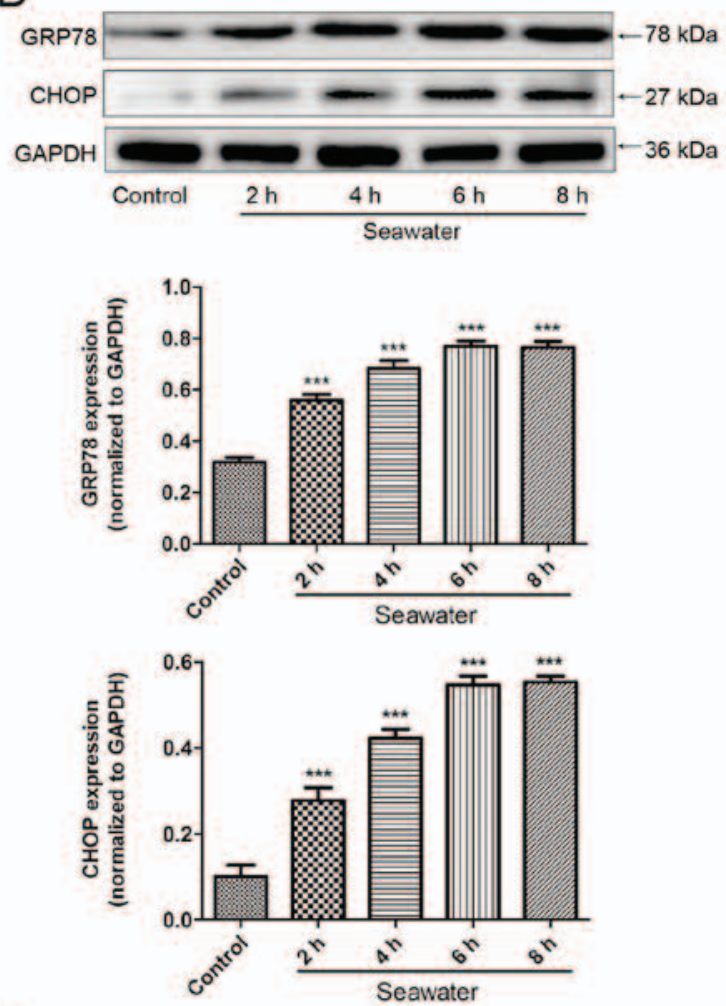
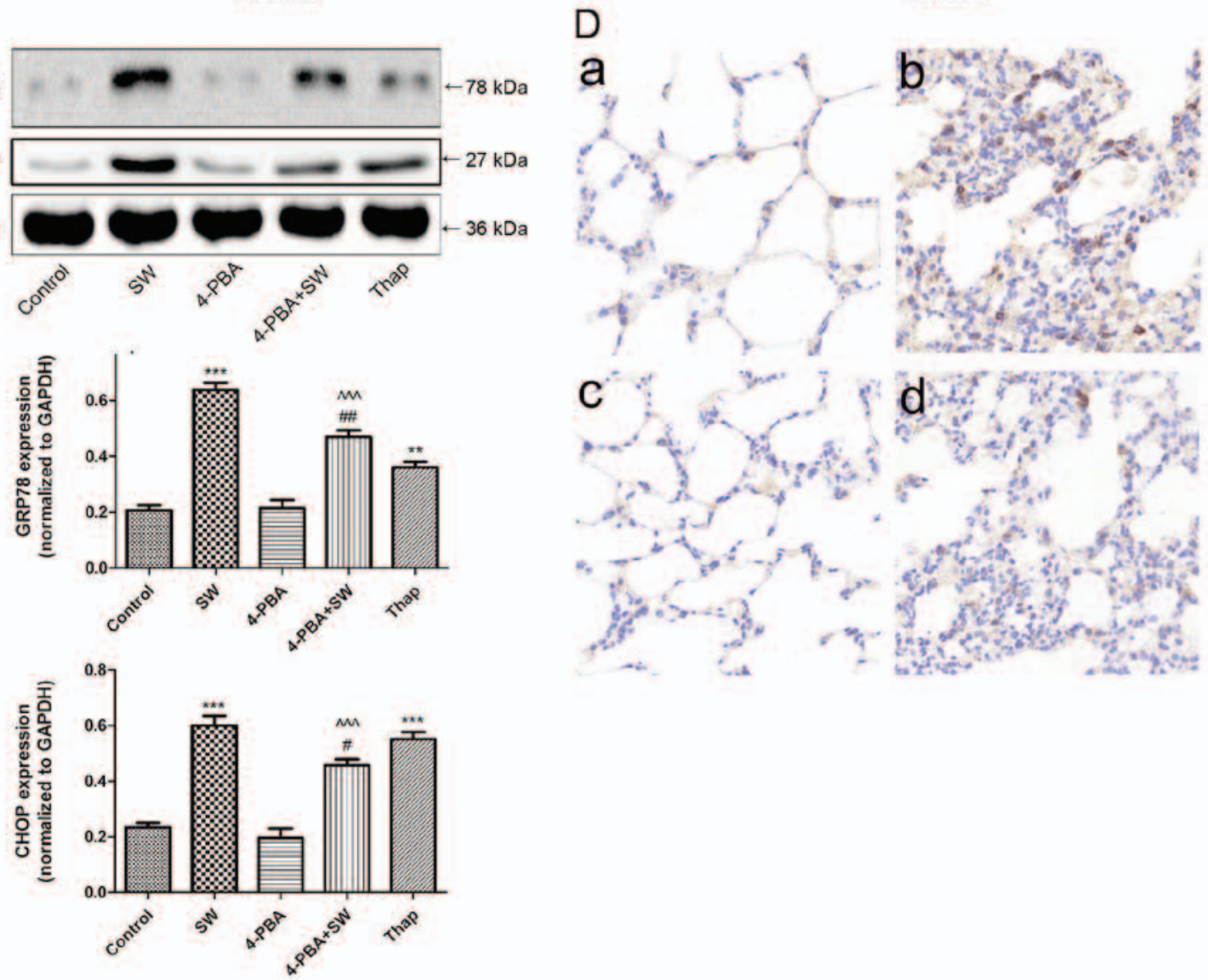

Figure 5. ER stress is activated by SW. Time-dependent effects of SW on the ER stress-associated proteins GRP78 and CHOP in (A) rat lungs and (B) A549 cells. A549 cells or rats were treated with SW for the indicated ti mes, and the expression levels of GRP78 and CHOP were assessed by western blot analysis. (C) Effects of ER stress inhibitors or activators on SW-induced ER stress in A549 cells. Following pretreatment with $2 \mathrm{mM} 4$-PBA or $150 \mathrm{nM}$ Thap alone as the positive control of SW for $2 \mathrm{~h}$, A549 cells were treated with $25 \%$ SW for $4 \mathrm{~h}$, and the expression of ER stress-associated proteins was assessed. (D) Effects of ER stress inhibitors on SW-induced ER stress in rat lungs. Following pretreatment with 4-PBA $(30 \mathrm{mg} / \mathrm{kg})$, the rats were treated with SW for $4 \mathrm{~h}$, and immunohistochemistry was used to detect GRP78 expression in rat lungs. (a) Control, (b) SW, (c) 4-PBA and (d) 4-PBA + SW groups (magnification, x10). Data are presented as the means \pm standard error of the mean, $\mathrm{n}=5 .{ }^{* *} \mathrm{P}<0.01$ and ${ }^{* * * *} \mathrm{P}<0.001$ vs. the control group; ${ }^{\prime \prime} \mathrm{P}<0.05$ and ${ }^{* \# \#} \mathrm{P}<0.01$ vs. the $\mathrm{SW}$ group; ${ }^{\wedge \wedge} \mathrm{P}<0.001$ vs. 4-PBA group. 4-PBA, 4-phenylbutyric acid; CHOP, CCAAT/enhancer binding protein homologous protein; ER, endoplasmic reticulum; SW, seawater; Thap, thapsigargin. 

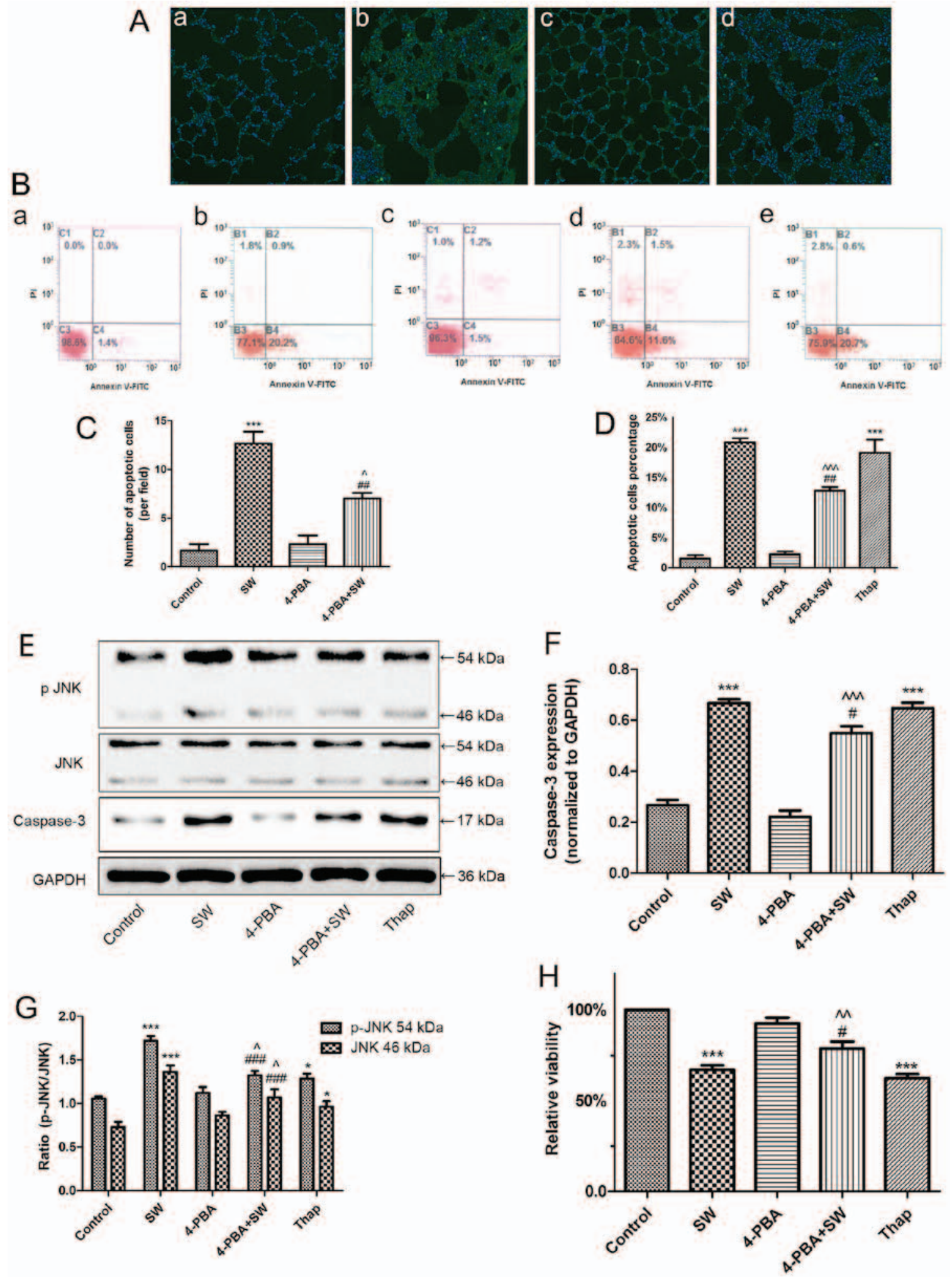

Figure 6. SW-induced cell apoptosis and growth inhibition are dependent on endoplasmic reticulum stress. (A) Effects of 4-PBA (30 mg/kg) on SW-induced apoptosis in rats (TUNEL staining). (a) Control, (b) SW, (c) 4-PBA and (d) 4-PBA + SW groups (magnification, x10). (B) Effects of 4-PBA (2 mM) or Thap $(150 \mathrm{nM})$ on SW-induced apoptosis of A549 cells (Annexin V-FITC/PI staining). (a) Control, (b) SW, (c) 4-PBA, (d) 4-PBA + SW and (e) Thap groups. (C) Number of apoptotic cells per field in (A). (D) Percentage of apoptotic cells in (B). (E-G) Effects of 4-PBA or Thap on the expression of apoptosis-associated proteins caspase-3 and p-JNK. (H) Effects of 4-PBA or Thap on SW-induced cell growth inhibition (Cell Counting kit-8 assay). Data are presented as the means \pm standard error of the mean, $n=5 .{ }^{*} \mathrm{P}<0.05$ and ${ }^{* * * *} \mathrm{P}<0.001$ vs. the control group; ${ }^{*} \mathrm{P}<0.05,{ }^{\# \#} \mathrm{P}<0.01$ and ${ }^{\# \# \#} \mathrm{P}<0.001$ vs. the $\mathrm{SW}$ group; ${ }^{\wedge} \mathrm{P}<0.05$, ${ }^{\wedge} \mathrm{P}<0.01$ and ${ }^{\wedge \wedge} \mathrm{P}<0.001$ vs. the 4-PBA group. 4-PBA, 4-phenylbutyric acid; FITC, fluorescein isothiocyanate; JNK, c-Jun N-terminal kinae; p-JNK, phosphorylated-JNK; PI, propidium iodide; SW, seawater; Thap, thapsigargin.

ALI is a syndrome that results from acute pulmonary inflammation, which is accompanied by epithelial cell damage and increased pulmonary effusion, thus resulting in pulmonary edema and respiratory failure $(1,23,24)$. The present study 

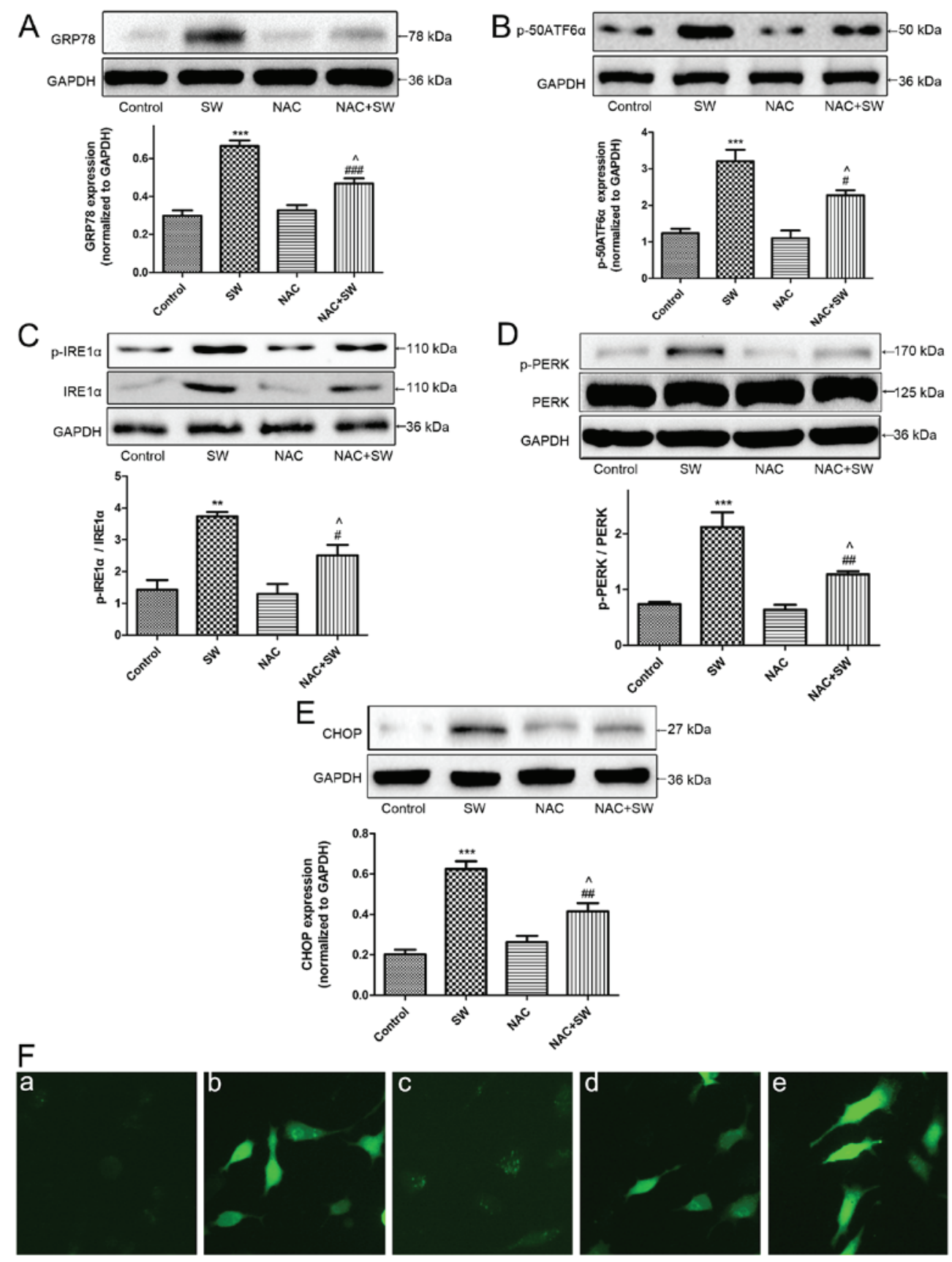

G

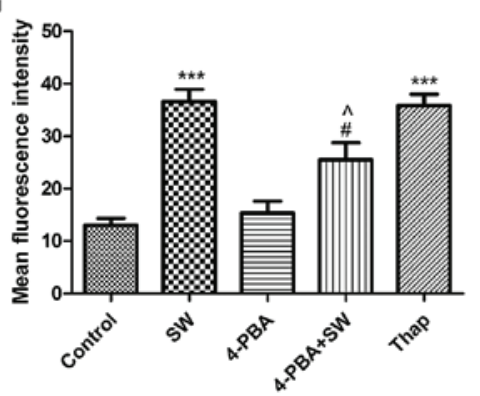

Figure 7. SW induces ROS and ER stress, which interact with each other. (A-E) Effects of NAC on SW-induced ER stress. Following pretreatment with $5 \mathrm{mM}$ NAC for $2 \mathrm{~h}$, cells were treated with 25\% SW for $4 \mathrm{~h}$; then, the expression of the ER stress-associated proteins GRP78, p-50ATF6 $\alpha, \mathrm{p}$-IRE1 $\alpha, \mathrm{p}-\mathrm{PERK}$ and CHOP was evaluated by western blot analysis. (F) Effects of 4-PBA or Thap on SW-induced ROS generation. Following pretreatment with 2 mM 4-PBA or $150 \mathrm{nM}$ Thap for $2 \mathrm{~h}$, cells were treated with $25 \% \mathrm{SW}$ for $4 \mathrm{~h}$, and cellular ROS levels were assessed using 2',7'-dichlorofluorescein diacetate and visualized with a fluorescence microscope (magnification, x100). (G) Mean fluorescence intensity of (F) was analyzed using ImageJ software. (a) Control, (b) SW, (c) 4-PBA and (d) $4-\mathrm{PBA}+\mathrm{SW}$ groups. Data are presented as the means \pm standard error of the mean, $\mathrm{n}=5 .{ }^{* * *} \mathrm{P}<0.01$ and ${ }^{* * * *} \mathrm{P}<0.001$ vs. the control group; ${ }^{*} \mathrm{P}<0.05$, ${ }^{\# \#} \mathrm{P}<0.01$ and ${ }^{\# \# \#} \mathrm{P}<0.001$ vs. the $\mathrm{SW}$ group; ${ }^{\wedge} \mathrm{P}<0.05$ vs. the NAC or 4-PBA group. 4-PBA, 4-phenylbutyric acid; ATF6 $\alpha$, activating transcription factor $6 \alpha$; CHOP, CCAAT/enhancer binding protein homologous protein; ER, endoplasmic reticulum; GRP78, glucose-regulated protien 78; IRE1 $\alpha$, inositol-requiring kinase $1 \alpha$; NAC, N-acetyl-L-cysteine; p-, phosphorylated; PERK, protien kinase R-like ER kinase; SW, seawater; Thap, thapsigargin. 
demonstrated that SW inhalation was able to induce marked histopathological alterations in rat lungs, which peaked at $4 \mathrm{~h}$. Furthermore, SW administration induced pulmonary edema, which was evidenced by measurement of the lung W/D ratio. SW exposure also inhibited A549 cell growth in vitro. Numerous studies have suggested that alveolar epithelial cell apoptosis serves an important role in the pathological process of ALI/ARDS (25-27). In the present in vitro study, the number of apoptotic cells exhibited a time-dependent increase when A549 cells were treated with SW. In addition, the number of apoptotic cells was increased in SW-treated rats compared with in control rats, and reached a peak at $4 \mathrm{~h}$. In addition, the degree of alveolar epithelial cell apoptosis was consistent with the trend in pathological alterations determined by H\&E staining. These results suggested that SW may induce cell apoptosis, growth inhibition and histopathological lesions, which may contribute to the pathological process of SW-ALI.

The term ROS refers to cellular oxygen free radicals, including superoxide $\left(\mathrm{O}_{2}{ }^{-}\right)$, hydrogen peroxide $\left(\mathrm{H}_{2} \mathrm{O}_{2}\right)$ and hydroxyl radical $\left({ }^{\circ} \mathrm{OH}\right)$, which can be generated as a result of exposure to toxic agents and as oxygen byproducts $(28,29)$. As a second messenger, ROS can regulate cell proliferation, apoptosis and transformation $(30,31)$. Therefore, the present study assessed whether ROS generation is involved in SW-induced cell growth inhibition and apoptosis. The present study indicated that SW dose- and time-dependently increased ROS generation in A549 cells. In addition, suppressing ROS generation by pretreating A549 cells with the ROS scavenger NAC significantly decreased the expression of p-JNK and caspase-3, which are both important in triggering apoptosis. Furthermore, NAC pretreatment ameliorated SW-induced apoptosis and histopathological alterations in rat lungs. These results suggested that SW inhalation-induced ALI/ARDS may partially depend on ROS generation.

The ER is an important regulator of protein synthesis and folding; when stimulated by external stimuli, misfolded and unfolded proteins accumulate in the ER cavity to activate the unfolded protein response (UPR), which is an ER stress response $(32,33)$. There are three ER-resident transmembrane proteins, namely PERK, ATF6 $\alpha$ and IRE1 $\alpha$, which can initiate the UPR to activate ER stress, and which may be involved in apoptosis $(19,33,34)$. Previous studies have suggested that CHOP can be activated by the UPR signaling pathways to induce apoptosis $(35,36)$. The present study revealed that SW exposure time-dependently upregulated the expression of the ER stress marker protein GRP78 in vitro. In addition, the expression levels of GRP78 were increased in rats with SW inhalation, and peaked at $4 \mathrm{~h}$. Notably, the alterations in CHOP expression were consistent with those in GRP78 expression in vitro and in vivo. Blocking ER stress with an ER stress inhibitor, 4-PBA, not only decreased the expression of SW-induced GRP78 and CHOP, but also decreased p-JNK and caspase-3 expression. Furthermore, 4-PBA pretreatment significantly improved rat lung cell apoptosis and histopathological alteration (Fig. 5D). These results suggested that SW-induced apoptosis and cell injury partially depend on ER stress, which may trigger CHOP and p-JNK and then activate the caspase-3 apoptosis signaling pathway.

Previous studies have suggested that ROS generation and ER stress are closely related; in particular, excessive accumulation of intracellular ROS can induce ER stress $(35,37)$. In addition, ER stress can increase ROS generation $(11,37)$. In the present study, blocking ROS generation with NAC decreased the expression of GRP78, p-PERK, p-IRE1 $\alpha$, p-50ATF6 $\alpha$ and $\mathrm{CHOP}$, thus suggesting that ROS generation was an upstream factor in the induction of SW-induced ER stress. Conversely, blocking ER stress with 4-PBA significantly decreased intracellular ROS generation. These results indicated that ROS generation and ER stress interact with each other to induce cell damage in response to SW exposure; however, the exact underlying mechanism requires further investigation.

In conclusion, the present study demonstrated that SW administration can trigger alveolar epithelial cell apoptosis and growth inhibition to induce ALI/ARDS, which may partially depend on ROS generation and the ER stress pathway. The involvement of ROS and the ER stress pathway in SW-ALI provides a potential clinical treatment strategy. However, the pathogenesis of SW-ALI is complex, and there are other signaling mechanisms involved in the regulation of alveolar epithelial cell apoptosis. In addition, the exact mechanism underlying the interaction between ROS generation and ER stress requires further investigation.

\section{Acknowledgements}

Not applicable.

\section{Funding}

The present study was supported by research grants from the National Natural Science Foundation of China (grant no. 81570067).

\section{Availability of data and materials}

We declared that materials described in the manuscript, including all relevant raw data, will be freely available to any scientist wishing to use them for non-commercial purposes, without breaching participant confidentiality.

\section{Authors' contributions}

PCL, YJL, DGM and FGJ conceived and designed the study. PCL, BRW, CCL, XL, YJL and WSQ performed the experiments. PCL, BRW and YJL wrote the paper. DGM and FGJ reviewed and edited the manuscript. All authors read and approved the manuscript.

\section{Ethics approval and consent to participate}

The present study was approved by the Animal Care and Use Committee of the Fourth Military Medical University (Xi'an, China).

\section{Consent for publication}

Not applicable.

\section{Competing interests}

The authors declare that they have no competing financial interests. 


\section{References}

1. Han F, Luo Y, Li Y, Liu Z, Xu D, Jin F and Li Z: Seawater induces apoptosis in alveolar epithelial cells via the Fas/FasL-mediated pathway. Respir Physiol Neurobiol 182: 71-80, 2012.

2. Soar J, Deakin CD, Nolan JP, Abbas G, Alfonzo A, Handley AJ, Lockey D, Perkins GD, Thies K; European Resuscitation Council: European Resuscitation Council guidelines for resuscitation 2005. Section 7. Cardiac arrest in special circumstances. Resuscitation 67 (Suppl 1): S135-S170, 2005.

3. Ibsen LM and Koch T: Submersion and asphyxial injury. Crit Care Med 30 (Suppl 11): S402-S408, 2002.

4. Matsuda N, Yamamoto S, Takano K, Kageyama S, Kurobe Y, Yoshihara Y, Takano Y and Hattori Y: Silencing of fas-associated death domain protects mice from septic lung inflammation and apoptosis. Am J Respir Crit Care Med 179: 806-815, 2009.

5. Kitamura Y, Hashimoto S, Mizuta N, Kobayashi A, Kooguchi K, Fujiwara I and Nakajima H: Fas/FasL-dependent apoptosis of alveolar cells after lipopolysaccharide-induced lung injury in mice. Am J Respir Crit Care Med 163: 762-769, 2001.

6. Li JH, Xu M, Xie XY, Fan QX, Mu DG, Zhang Y, Cao FL, Wang YX, Zhao PT, Zhang B, et al: Tanshinone IIA suppresses lung injury and apoptosis, and modulates protein kinase B and extracellular signal-regulated protein kinase pathways in rats challenged with seawater exposure. Clin Exp Pharmacol Physiol 38: 269-277, 2011.

7. Li ZY, Yang Y, Ming M and Liu B: Mitochondrial ROS generation for regulation of autophagic pathways in cancer. Biochem Biophys Res Commun 414: 5-8, 2011.

8. Mazure NM and Pouysségur J: Hypoxia-induced autophagy: Cell death or cell survival? Curr Opin Cell Biol 22: 177-180, 2010.

9. Joyce MA, Walters KA, Lamb SE, Yeh MM, Zhu LF, Kneteman N, Doyle JS, Katze MG and Tyrrell DL: HCV induces oxidative and ER stress, and sensitizes infected cells to apoptosis in SCID/Alb-uPA mice. PLoS Pathog 5: e1000291, 2009.

10. Park IJ, Yang WK, Nam SH, Hong J, Yang KR, Kim J, Kim SS, Choe W, Kang I and Ha J: Cryptotanshinone induces G1 cell cycle arrest and autophagic cell death by activating the AMP-activated protein kinase signal pathway in $\mathrm{HepG} 2$ hepatoma. Apoptosis 19: 615-628, 2014.

11. Malhotra JD and Kaufman RJ: Endoplasmic reticulum stress and oxidative stress: A vicious cycle or a double-edged sword? Antioxid Redox Signal 9: 2277-2293, 2007.

12. National Institutes of Health (NIH) publication No 85-23, revised in 1985 .

13. Lu TH, Su CC, Tang FC, Chen CH, Yen CC, Fang KM, Lee I, Hung DZ and Chen YW: Chloroacetic acid triggers apoptosis in neuronal cells via a reactive oxygen species-induced endoplasmic reticulum stress signaling pathway. Chem Biol Interact 225: 1-12, 2015.

14. Ott M, Gogvadze V, Orrenius S and Zhivotovsky B: Mitochondria, oxidative stress and cell death. Apoptosis 12: 913-922, 2007.

15. Wang WY, Albert CJ and Ford DA: Alpha-chlorofatty acid accumulates in activated monocytes and causes apoptosis through reactive oxygen species production and endoplasmic reticulum stress. Arterioscler Thromb Vasc Biol 34: 526-532, 2014.

16. Moungjaroen J, Nimmannit U, Callery PS, Wang L, Azad N, Lipipun V, Chanvorachote P and Rojanasakul Y: Reactive oxygen species mediate caspase activation and apoptosis induced by lipoic acid in human lung epithelial cancer cells through Bcl-2 downregulation. J Pharmacol Exp Ther 319: 1062-1069, 2006.

17. Zhou Y, Shu F, Liang X, Chang H, Shi L, Peng X, Zhu J and Mi M: Ampelopsin induces cell growth inhibition and apoptosis in breast cancer cells through ROS generation and endoplasmic reticulum stress pathway. PLoS One 9: e89021, 2014.

18. Quick QA and Faison MO: CHOP and caspase 3 induction underlie glioblastoma cell death in response to endoplasmic reticulum stress. Exp Ther Med 3: 487-492, 2012.

19. Szegezdi E, Logue SE, Gorman AM and Samali A: Mediators of endoplasmic reticulum stress-induced apoptosis. EMBO Rep 7: 880-885, 2006.
20. Han J, Back SH, Hur J, Lin YH, Gildersleeve R, Shan J, Yuan CL, Krokowski D, Wang S, Hatzoglou M, et al: ER-stress-induced transcriptional regulation increases protein synthesis leading to cell death. Nat Cell Biol 15: 481-490, 2013.

21. Syed DN, Lall RK, Chamcheu JC, Haidar O and Mukhtar H: Involvement of ER stress and activation of apoptotic pathways in fisetin induced cytotoxicity in human melanoma. Arch Biochem Biophys 563: 108-117, 2014

22. Hou CH, Lin FL, Hou SM and Liu JF: Hyperthermia induces apoptosis through endoplasmic reticulum and reactive oxygen species in human osteosarcoma cells. Int J Mol Sci 15: 17380-17395, 2014.

23. Gropper MA and Wiener-Kronish J: The epithelium in acute lung injury/acute respiratory distress syndrome. Curr Opin Crit Care 14: 11-15, 2008.

24. Flecknoe S, Harding R, Maritz G and Hooper SB: Increased lung expansion alters the proportions of type I and type II alveolar epithelial cells in fetal sheep. Am J Physiol Lung Cell Mol Physiol 278: L1180-L1185, 2000.

25. Perl M, Lomas-Neira J, Chung CS and Ayala A: Epithelial cell apoptosis and neutrophil recruitment in acute lung injury-a unifying hypothesis? What we have learned from small interfering RNAs. Mol Med 14: 465-475, 2008.

26. Imazu Y, Yanagi S, Miyoshi K, Tsubouchi H, Yamashita S, Matsumoto N, Ashitani J, Kangawa K and Nakazato M: Ghrelin ameliorates bleomycin-induced acute lung injury by protecting alveolar epithelial cells and suppressing lung inflammation. Eur J Pharmacol 672: 153-158, 2011.

27. Miyake Y, Kaise H, Isono K, Koseki H, Kohno K and Tanaka M: Protective role of macrophages in noninflammatory lung injury caused by selective ablation of alveolar epithelial type II cells. J Immunol 178: 5001-5009, 2007.

28. Sen CK and Packer L: Antioxidant and redox regulation of gene transcription. FASEB J 10: 709-720, 1996.

29. Al-Mehdi AB, Pastukh VM, Swiger BM, Reed DJ, Patel MR, Bardwell GC, Pastukh VV, Alexeyev MF and Gillespie MN: Perinuclear mitochondrial clustering creates an oxidant-rich nuclear domain required for hypoxia-induced transcription. Sci Signal 5: ra47, 2012.

30. Dalton TP, Shertzer HG and Puga A: Regulation of gene expression by reactive oxygen. Annu Rev Pharmacol Toxicol 39: 67-101, 1999.

31. Azad MB, Chen Y and Gibson SB: Regulation of autophagy by reactive oxygen species (ROS): Implications for cancer progression and treatment. Antioxid Redox Signal 11: 777-790, 2009.

32. Feldman DE, Chauhan V and Koong AC: The unfolded protein response: A novel component of the hypoxic stress response in tumors. Mol Cancer Res 3: 597-605, 2005.

33. Mandl J, Mészáros T, Bánhegyi G and Csala M: Minireview: Endoplasmic reticulum stress: Control in protein, lipid, and signal homeostasis. Mol Endocrinol 27: 384-393, 2013.

34. Szegezdi E, Fitzgerald U and Samali A: Caspase-12 and ER-stress-mediated apoptosis: The story so far. Ann NY Acad Sci 1010: 186-194, 2003.

35. McCullough KD, Martindale JL, Klotz LO, Aw TY and Holbrook NJ: Gadd153 sensitizes cells to endoplasmic reticulum stress by downregulating $\mathrm{Bcl} 2$ and perturbing the cellular redox state. Mol Cell Biol 21: 1249-1259, 2001.

36. Woo KJ, Lee TJ, Lee SH, Lee JM, Seo JH, Jeong YJ, Park JW and Kwon TK: Elevated gadd153/chop expression during resveratrol-induced apoptosis in human colon cancer cells. Biochem Pharmacol 73: 68-76, 2007.

37. Pierre AS, Minville-Walz M, Fèvre C, Hichami A, Gresti J, Pichon L, Bellenger S, Bellenger J, Ghiringhelli F, Narce M, et al: Trans-10, cis-12 conjugated linoleic acid induced cell death in human colon cancer cells through reactive oxygen species-mediated ER stress. Biochim Biophys Acta 1831: 759-768, 2013.

This work is licensed under a Creative Commons Attribution-NonCommercial-NoDerivatives 4.0 International (CC BY-NC-ND 4.0) License. 